\title{
BREAST SELF EXAMINATION; SIGNIFICANT TOOL IN EARLY DETECTION OF BREAST CANCER
}

\author{
Saima khan ${ }^{1 \& 4}$, Sadaf Ahmed ${ }^{1 \& 2}$, Nelofer Sultana ${ }^{3}$ \& Shamoon Noushad ${ }^{1 \& 4}$ \\ 1. Advance Educational Institute \& Research Centre (AEIRC) \\ 2. University Of Karachi \\ 3, SMBBMC \\ 4, Dow University of Health Sciences \\ Corresponding Author Email: saima.aeirc@gmail.com
}

\begin{abstract}
This evidence based study is to provide the awareness of breast self examination; its outcomes and significance. There is a never matching increase noted in the incidences of breast cancer worldwide. Pakistani women are on top of the list in the region to develop this disease and it has also been observed that they diagnose to have higher grade disease in early age. Early detection followed by timely treatment is the best prognosis for long term survival. This a retrospective study in which the data was gathered through questionnaire for the selected variables. Out of 100 patients 49 were doing BSE while 51 were unaware of breast self-examination. Out of these $49 \%, 42 \%$ were doing BSE randomly, $2 \%$ were doing monthly,3\% were doing weekly while $2 \%$ were doing on daily bases, and $24(49 \%)$ patients were found to have microscopically confirmed carcinoma and 12 (24\%) were found to have negative microscopic exams remaining $13(27 \%)$ patients who were doing BSE were not gone through microscopic exam. Breast self-examination is the simplest tool that can play an important role in the detection of breast cancer. There is need to encourage BSE practices among the women along with the development of awareness program to make it successful.
\end{abstract}

\section{KEYWORDS}

Breast self-examination, breast cancer, early detection, Breast awareness

\section{BACKGROUND}

There is a never matching increase noted in the incidences of breast cancer worldwide. Pakistani women are on top of the list in the region to develop this disease and it has also been observed that they diagnose to have higher grade disease in early age. Early detection followed by timely treatment is the best prognosis for long term survival. Breast self-examination (BSE) has been proposed as a way of reducing the breast cancer problems and may be a valuable approach, in countries where entire female population are at higher risk due to unavailability of sophisticated screening services (Hall, 1997). The concept of BSE is not new and has been enthusiastically proclaimed in numerous countries for several years. On the other hand, its real value has been questioned by number of investigators researchers who believes that doing BSE is not appropriate because of its apparent simplicity, without evidences that's supports or proves its efficacy (Miller, 1985). BSE is inexpensive and safe that could possibly be done by nearly all women if they are effectively trained and motivated. BSE may be more sensitive than a clinical breast examination or mammography because women may be capable of detecting fine changes in their own breasts that might not be noticeable by other health professionals on manual palpation. There is a belief that among women who practice BSE and develop carcinoma of breast are more likely to find it at earlier stage, is expected to lead to earlier treatment and hence decrease their risk of dying from the breast cancer. Studies suggests that women practicing BSE have an increased survival as they are more likely to locate their breast tumor or lump themselves either it can be benign or malignant, that are probably in earlier stage or smaller in size (Hackshaw, 1996; IARC, 2002; Hackshaw, 2003). Women who practiced BSE were more likely to consult a physician without delay. The more frequently BSE was performed, the more likely was cancer to be discovered by BSE and when cancer was discovered by BSE it was at an earlier stage than after any other method of discovery except mammography. The earlier stage of breast cancer found in BSE users within each educational level or age or any ethnic group, at each socioeconomic level strongly suggests that the practice of BSE itself plays an important role in early diagnosis. BSE is not the final answer, but it is a significant step forward in the continuing struggle against cancer of the breast (Huguley, 1985). During the last 10 years, therefore, attempts have been made to determine the effectiveness of breast self-examination in detection of breast cancer. Most studies showed that BSE can of greater help and led to the disease being diagnosed at an earlier stage (Esquerra, 1984; Semiglazov, 1999). Earlier diagnosis evidently depends upon improving the diagnostic skill of the patient. The likelihood of BSE practice whether on weekly bases or monthly bases and its competency with which it is done were strongly related to the source of knowledge. A greater proportion of women doing BSE had their tumors found by mammography than of women not doing BSE.A study strongly suggests that the practice of BSE itself plays an important role in early diagnosis. BSE is not the final answer, but it is significant step forward in the continuing struggle against cancer of the breast.

\section{METHOD}

This a retrospective study in which the data was gathered through self-questionnaire for the selected variables from territory care Hospital of Karachi and the data was analyzing by using SPSS software .Personal and family history of breast disease, information relating to the practice and frequency of BSE were obtained from patients through questionnaire. 


\section{RESULTS}

Out of 100 data $75 \%$ were with no history of cancer, in which 37 $(49.33 \%)$ were doing breast self-examination whereas 38 (50.66\%) were unaware of performing breast self-examination. Out of 49.33\% (those practicing BSE), $42 \%$ were doing BSE randomly, $2 \%$ were doing monthly, $3 \%$ were doing weekly while $2 \%$ were doing on daily bases. Also out of these $49.33 \%$ (those practicing
BSE), $60 \%$ were performing exam for routine purpose, $20 \%$ were having pain/mastalgia, $9 \%$ with lumps, $3 \%$ were with swelling, $4 \%$ were with discharge, $3 \%$ having cyst and $1 \%$ felt scar. In the remaining $25 \%$ patients that are diagnosed with cancer, $48 \%$ were practicing BSE while $52 \%$ were not practicing BSE.

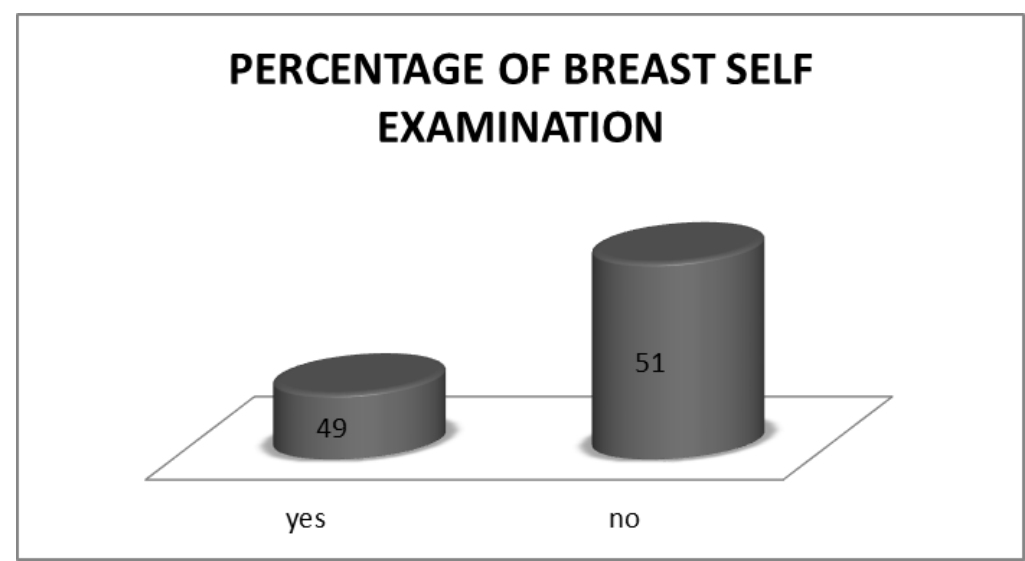

Figure 1 showing percentage of female performing Breast self -Examination

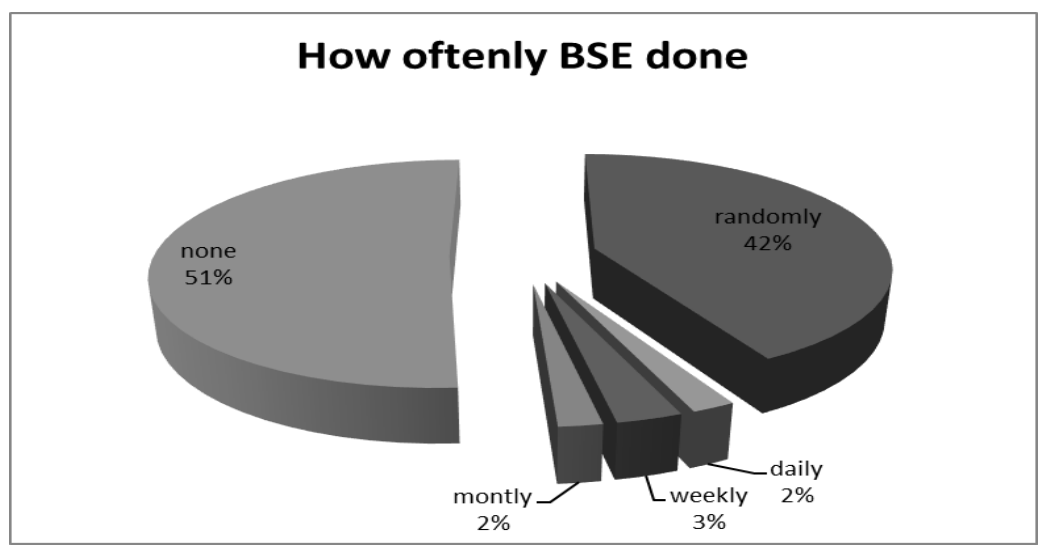

Figure 2 showing how frequently female perform BSE.

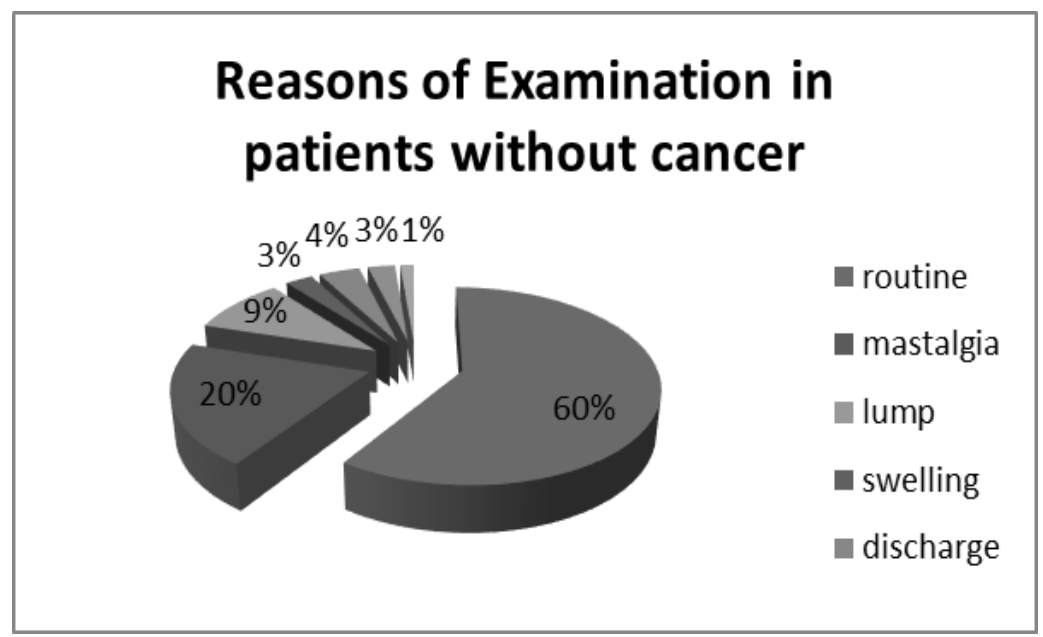

Figure 3 showing percentage of Reasons for mammography other than malignancy 


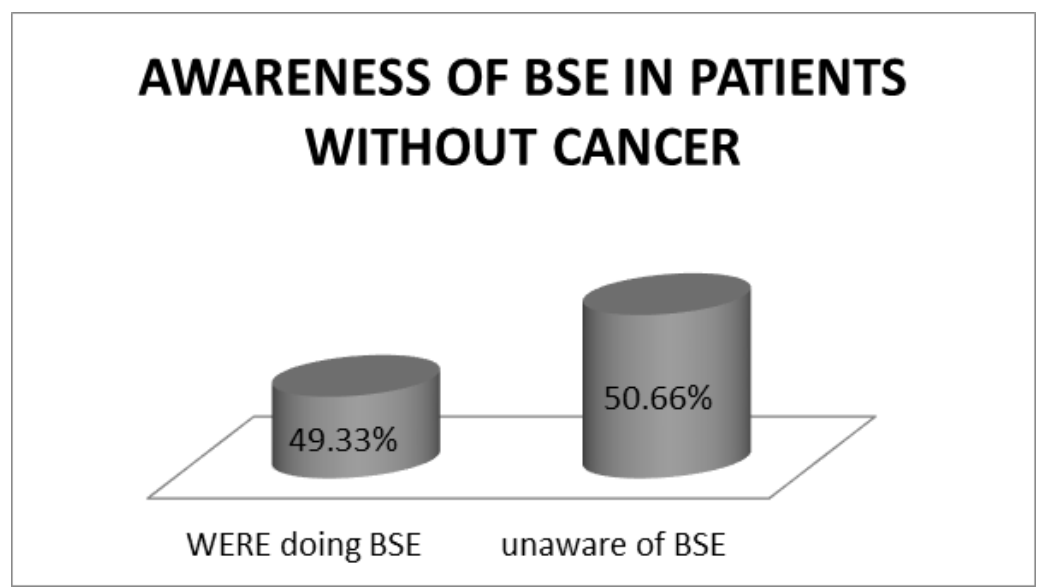

Figure 4 showing awareness of BSE in females without malignancy

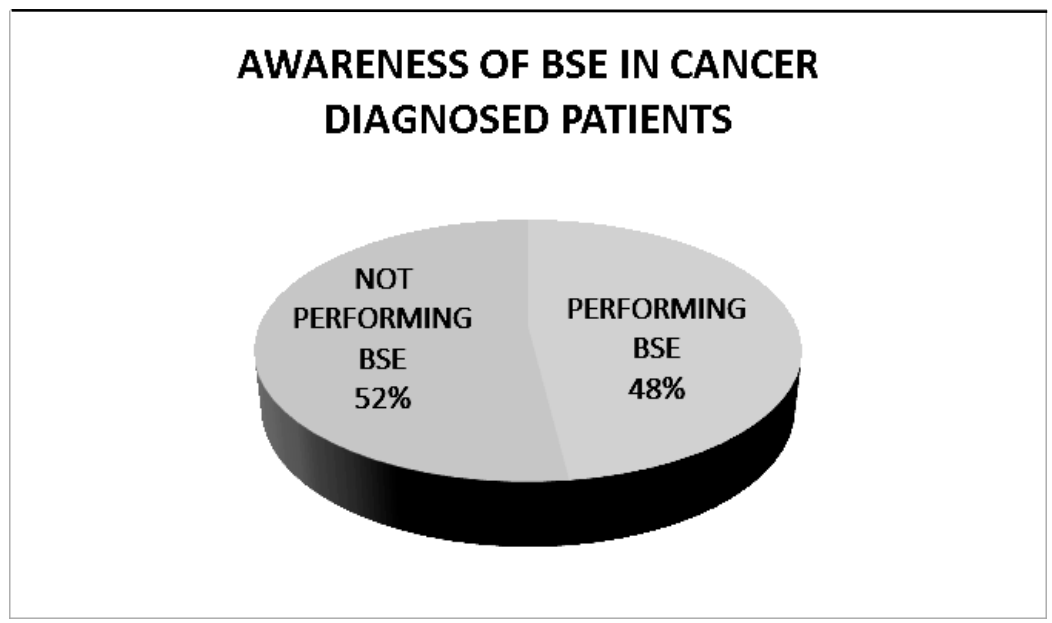

Figure 5 showing awareness of BSE in cancer diagnosed patients

\section{DISCUSSION}

Breast self-examination was generally accepted to be a good thing, offering women the possibility of self-determination and selfawareness as well as protection against death from breast cancer. Unlike to mammography and clinical breast examination, BSE is has its significance not only as it is simple, inexpensive but also its teaching is possible to both health professionals and women and more importantly it can be means of raising awareness about breast cancer in women. It is also argued that in many developed or under developing countries, BSE may be the only realistic approach towards early detection of breast cancer (Mittra, 2000) however there are no clear evidences that supports the efficacy of performing routine BSE in early detection and cause specific mortality due to breast cancer. While there are number of studies found that BSE has improved early detection and reduces mortality (Montazeri, 2008; Lam, 2008). Researchers generally agreed in that early detection of cancer increases the chance of cure (Berg, 1966; Say, 1974; Shapiro, 1977) and it has also frequently been observed that most breast cancers are found by the women, not their physician (Hickey, 1957; Smith, 1980; Senie, 1981).
Women performing breast self-examination more frequently were significantly more likely to detect their breast cancer themselves. The time period between first recognition of a symptom or sign of breast cancer and the histologic diagnosis of breast cancer was somewhat shorter in women performing breast self-examination . There was little relationship between the length of delay and breast self-examination frequency when monthly breast Selfexamination performers were compared to less than monthly examiners. According to the above study those doing BSE, frequency of performing BSE varies on monthly, weekly or daily basis. This study showed that females may not have sufficient knowledge about BSE and low level of awareness has been reported. It is also showed that even after having breast cancer once, even then these females were less interested in Breast selfexamination which might be due to lack of knowledge and awareness. It is possible that careful instruction and routine practice would sufficiently improve BSE proficiency to enable a woman to be as effective in examining her own breasts as a trained professional. Similarly the awareness of risk factors and early warning signs of the disease among different groups were below average. Breast health awareness provides women with some acknowledgement of the part they can play in being empowered to fight breast disease. 


\section{CONCLUSION}

Breast self-examination is the simplest tool that can play an important role in the early detection of breast cancer. Using this tool breast cancer may be detected when they are at an earlier stage and are smaller than in women diagnosed with breast cancer without practicing BSE. There is also high need to encourage BSE practices among the women along with the development of awareness program to make it successful.

\section{REFERENCES}

- $\quad$ Berg, J. W., \& Robbins, G. F. (1966). Factors influencing short and long term survival of breast cancer patients. Surgery, gynecology \& obstetrics, 122(6), 13111316.

- $\quad$ Esquerra Jr Jr, R. M. F., French, E. S., \& Frost, O. (1984). Breast self-examination practices and breast cancer survival. Cancer, 53, 999-1005.

- Hackshaw, A. K. (1996). Screening for breast cancer in young women using breast self-examination. In EvidenceGuided Prescribing of the Pill, Hannaford PC, Webb AMC (eds). Royal College of General Practitioners. Parthenon Publishing Group, Lancs, UK, 217-226.

- Hackshaw, A. K., \& Paul, E. A. (2003). Breast selfexamination and death from breast cancer: a metaanalysis. British journal of cancer, 88(7), 1047-1053.

- Hall, D. C., Goldstein, M. K., \& Stein, G. H. (1977). Progress in manual breast examination. Cancer, 40(1), 364-370.

- $\quad$ Hickey, R. C. (1957). Cancer of the breast, 1,661 patients. II. Considerations in the failure to cure after radical mastectomy. The American journal of roentgenology, radium therapy, and nuclear medicine, 77(3), 421-430.

- Huguley, C. M., \& Brown, R. L. (1981). The value of breast self-examination.Cancer, 47(5), 989-995.

- International Agency for Research on Cancer (IARC) (2002). Efficacy of screening by self-examination In Handbook of Cancer Prevention. Vol 7: Breast Cancer Screening, Vainio H, Bianchini F (eds). Lyon, France: IARC
- $\quad$ Lam, W. W., Chan, C. P., Chan, C. F., Mak, C. C., Chong, K. W., Leung, M. H., \& Tang, M. H. (2008). Factors affecting the palpability of breast lesion by selfexamination. Singapore medical journal, 49(3), 228-232.

- $\quad$ Miller, A. B., Chamberlain, J., \& Tsechkovski, M. (1985). Self-examination in the early detection of breast cancer: a review of the evidence, with recommendations for further research. Journal of chronic diseases, 38(6), 527-540.

- $\quad$ Mittra, I., Baum, M., Thornton, H., \& Houghton, J. (2000). Is clinical breast examination an acceptable alternative to mammographic screening? Bmj, 321(7268), 1071-1073.

- Montazeri, A., Vahdaninia, M., Harirchi, I., Harirchi, A. M., Sajadian, A., Khaleghi, F., \& Jarvandi, S. (2008). Breast cancer in Iran: need for greater women awareness of warning signs and effective screening methods. Asia Pac Fam Med, 7(1), 6 .

- $\quad$ Say, C. C., \& Donegan, W. L. (1974). Invasive carcinoma of the breast: prognostic significance of tumor size and involved axillary lymph nodes. Cancer, 34(2), 468-471.

- Semiglazov, V. F., Moiseyenko, V. M., Manikhas, A. G., Protsenko, S. A., Kharikova, R. S., Ivanov, V. G., ... \&Ivanova, O. A. (1999). Role of breast self-examination in early detection of breast cancer: Russia/WHO prospective randomized trial in St. Petersburg. Cancer Strategy, 1, 145151.

- $\quad$ Senie, R. T., Rosen, P. P., Lesser, M. L., \& Kinne, D. W. (1981). Breast self-examination and medical examination related to breast cancer stage. American Journal of Public Health, 71(6), 583-590.

- Shapiro, S. (1977). Evidence on screening for breast cancer from a randomized trial. Cancer, 39(6), 2772-2782.

- Smith, E. M., Francis, A. M., \& Polissar, L. (1980). The effect of breast self-exam practices and physician examinations on extent of disease at diagnosis. Preventive medicine, 9(3),409-417. 
